\title{
EFIKASI HERBISIDA GLIFOSAT UNTUK MENGENDALIKAN GULMA PADA PERTANAMAN KOPI (Coffea canephora) MENGHASILKAN
}

\author{
Debora Rosalyn Sigalingging, Dad RJ Sembodo \& Nanik Sriyani \\ Jurusan Agroteknologi, Fakultas Pertanian Universitas Lampung \\ Jl. Prof. Soemantri Brodjonegoro, No.1 Bandar Lampung 35145 \\ E-mail : raramaura@ rocketmail.com
}

\begin{abstract}
ABSTRAK
Dalam usaha peningkatan produksi tanaman kopi salah satu faktor yang perlu diperhatikan adalah pemeliharaan tanaman khususnya pengendalian gulma. Pengendalian gulma pada perkebunan kopi yang dinilai cukup efektif dan efisien yaitu dengan pengendalian secara kimiawi menggunakan herbisida berbahan aktif glifosat. Herbisida berbahan aktif glifosat merupakan herbisida yang bersifat non selektif dan memiliki spektrum pengendalian yang luas. Tujuan penelitian adalah (1) mengetahui kinerja herbisida glifosat dalam mengendalikan gulma pada pertanaman kopi menghasilkan dan (2) mengetahui tingkat toksisitas herbisida glifosat terhadap tanaman kopi menghasilkan. Penelitian terdiri dari enam perlakuan yang disusun dalam rancangan acak kelompok dengan empat ulangan. Perlakuan yang diuji yaitu glifosat $1,08 \mathrm{~kg} \mathrm{ha}^{-1}$, glifosat 1,44 $\mathrm{kg} \mathrm{ha}^{-1}$, glifosat 1,80 $\mathrm{kg} \mathrm{ha}^{-1}$, dan glifosat 2,16 $\mathrm{kg} \mathrm{ha}^{-1}$, penyiangan manual, dan kontrol. Data dianalisis ragam dan uji lanjut dengan Uji Beda Nyata Terkecil (BNT). Hasil penelitian menunjukkan bahwa (1) aplikasi herbisida glifosat pada dosis 1,08-2,16 kg ha-1 mampu menekan penutupan dan bobot kering gulma total, bobot kering gulma golongan daun lebar dan golongan rumput hingga 12 MSA dan (2) perlakuan herbisida glifosat yang digunakan untuk mengendalikan gulma tidak meracuni tanaman kopi hingga 6 MSA.
\end{abstract}

Kata kunci : glifosat, gulma, kopi

\section{PENDAHULUAN}

Tanaman kopi merupakan komoditas ekspor yang banyak dikembangkan dalam bentuk perkebunan oleh pihak perorangan maupun perusahaan swasta. Produksi kopi nasional mencapai 633.991 ton tahun 2011, dengan produktivitas rata-rata nasional $672 \mathrm{~kg} \mathrm{ha}^{-1}$. Berkaitan dengan prospek tanaman kopi yang cukup bagus di pasar dunia, maka pemerintah melaksanakan kegiatan intensifikasi dan perluasan areal pertanaman kopi (Direktorat Jenderal Perkebunan Kementrian Pertanian RI, 2012). Salah satu bentuk kegiatan intensifikasi yang dapat dilakukan yaitu pengendalian gulma di areal pertanaman kopi yang merupakan kompetitor tanaman kopi.

Pengaruh negatif gulma terhadap tanaman budidaya dapat terjadi karena kompetisi (nutrisi, air, cahaya dan $\mathrm{CO} 2$ ), produksi senyawa penghambat pertumbuhan (alelopati), sebagai inang jasad pengganggu tanaman (serangga hama atau patogen penyakit), serta menurunkan kualitas hasil karena adanya kontaminasi dari bagian-bagian gulma (Tjitrosoedirdjo dkk., 1984). Pengendalian gulma dapat dilakukan untuk membatasi investasi gulma sedemikian rupa sehingga tanaman dapat dibudidayakan secara produktif dan efisien atau merupakan prinsip mempertahankan kerugian minimum yaitu menekan populasi gulma sampai pada tingkat populasi yang tidak merugikan secara ekonomi (FroudWilliams, 2002 dalam Mas'ud, 2009). Berbagai metode pengendalian gulma dapat diterapkan pada budidaya kopi. Salah satu metode tersebut adalah pengendalian kimiawi. Pengendalian kimiawi, yaitu penggunaan herbisida, merupakan metode yang paling banyak digunakan karena tingkat efisiensi dan efektivitas yang tinggi.

Glifosat adalah salah satu jenis bahan aktif herbisida yang sangat sering digunakan dibandingkan bahan aktif lainnya dan digunakan secara luas dalam bidang pertanian karena efisiensi dan efektivitasnya (Cox, 2004). Glifosat termasuk herbisida non selektif, yang artinya mengendalikan secara luas semua jenis gulma. Herbisida tersebut diabsorbsi lewat daun, dan tidak aktif bila diaplikasikan lewat tanah. Translokasi glifosat terjadi ke seluruh bagian tumbuhan termasuk bagian tumbuhan yang ada di dalam tanah karena glifosat merupakan herbisida sistemik (Tomlin, 2009).

Herbisida GrindUp 480 SL yang berbahan aktif glifosat perlu diuji efektivitasnya dalam berbagai dosis untuk mengendalikan gulma pada pertanaman kopi menghasilkan, sebab herbisida tersebut merupakan formulasi baru dan belum terdaftar pada Komisi Pestisida untuk digunakan pada budidaya kopi. Melalui penelitian 
ini dapat diketahui daya kerja herbisida glifosat terhadap gulma pada kopi dan tingkat toksisitas pada tanaman kopi menghasilkan.

\section{BAHAN DAN METODE}

Penelitian dilaksanakan pada areal perkebunan kopi menghasilkan milik Balai Pengkajian Teknologi Pertanian di Kecamatan Natar Lampung Selatan dan Laboratorium Gulma Universitas Lampung dari bulan November 2012 sampai bulan Februari 2013. Alat-alat yang digunakan adalah knapsack sprayer, gelas ukur, pipet, timbangan, oven, kuadran berukuran 0,5 $\mathrm{m}$ x 0,5 $\mathrm{m}$, cutter/pisau dan ember plastik. Bahan-bahan yang digunakan antara lain klon/jenis kopi robusta berumur 5 tahun, pupuk, herbisida yang berbahan aktif isopropilamina glifosat (GrindUp $480 \mathrm{SL}$ ), dan air.

Penelitian terdiri dari enam perlakuan (Tabel 1) yang disusun dalam rancangan acak kelompok dengan empat ulangan. Pengolahan data dilakukan dengan menggunakan analisis ragam, homogenitas ragam diuji dengan uji Bartlet, aditivitas data diuji dengan uji Tukey, perbedaan nilai tengah perlakuan diuji dengan uji BNT pada taraf $5 \%$.

Petak percobaan dibuat dengan ukuran $3 \mathrm{~m} \times 15 \mathrm{~m}$ sebanyak 24 petak dan tiap petak terdiri dari 6 tanaman kopi dengan jarak tanam $3 \mathrm{~m} \times 2,5 \mathrm{~m}$. Variabel yang diamati meliputi: penutupan gulma total, bobot kering gulma total, bobot kering gulma golongan daun lebar, bobot kering gulma golongan rumput dan fitotoksisitas. Aplikasi herbisida dilakukan dengan cara menggunakan sprayer punggung semi otomatis dengan nozle warna biru. Aplikasi herbisida dilakukan pada saat kondisi penutupan gulma tidak kurang dari $75 \%$ dan dilakukan pada sebelah kanan dan kiri baris tanaman kopi.

Penyiangan mekanis dilakukan pada saat 0,4 , dan 8 minggu setelah aplikasi (MSA) herbisida glifosat pada petak perlakuan mekanis dengan menggunakan cangkul, sedangkan untuk kontrol tidak dilakukan aplikasi herbisida dan penyiangan mekanis. Pengamatan bobot kering gulma dilakukan dengan mengambil 2 contoh per petak percobaan. Pengambilan contoh menggunakan kuadran berukuran $0,5 \mathrm{~m} \times 0,5 \mathrm{~m}$ dengan cara memotong gulma setinggi permukaan tanah. Gulma dipilah berdasarkan golongannya dan dikeringkan dalam oven pada suhu $80^{\circ} \mathrm{C}$ selama 48 jam hingga bobot keringnya konstan, kemudian ditimbang.

\section{HASIL DAN PEMBAHASAN}

Penutupan gulma total. Berdasarkan Tabel 2 juga dapat diketahui bahwa pada 4 dan 12 MSA seluruh perlakuan herbisida dapat menekan penutupan gulma lebih baik dibanding perlakuan mekanis dan antar dosis herbisida tidak terdapat perbedaan daya kerja. Sedangkan pada 8 MSA, perlakuan herbisida glifosat $1,08 \mathrm{~kg} /$ ha memiliki daya kendali yang sama dengan perlakuan mekanis. Hal tersebut menunjukkan bahwa seluruh perlakuan yang diaplikasikan masih mampu menekan penutupan gulma dengan baik sampai dengan 12 MSA. Apabila bobot kering tumbuhan tetap atau berkurang maka dapat diduga bahwa terjadi gangguan dalam proses metabolisme tumbuhan tersebut. Gangguan tersebut dikarenakan herbisida glifosat terserap dengan baik oleh gulma kemudian ditranslokasikan ke seluruh jaringan tumbuhan yang masih muda dan aktif membelah melalui floem. Efek terjadinya hampir sama merata ke seluruh bagian gulma, mulai dari bagian daun sampai perakaran. Dengan demikian, proses pertumbuhan kembali juga terjadi sangat lambat sehingga rotasi pengendalian dapat lebih lama (Riadi, 2011).

Bobot kering gulma total. Tabel 4 menunjukkan bahwa pada 4, 8 dan 12 MSA perlakuan herbisida glifosat mampu menekan bobot kering gulma total sebesar $95 \%$ - 100\%. Pada 4 dan 12 MSA semua perlakuan herbisida glifosat mampu mengendalikan pertumbuhan gulma total dan antar dosis herbisida yang diaplikasikan tidak menunjukkan adanya perbedaan dalam menekan

Tabel 1. Susunan perlakuan

\begin{tabular}{clccc}
\hline \multirow{2}{*}{ No } & & \multirow{2}{*}{ Posis ha $^{-1}$} \\
\cline { 3 - 4 } & & ${\text { Formulasi }\left(1 \mathrm{ha}^{-1}\right)}^{\text {Bahan Aktif }\left(\mathrm{kg} \mathrm{ha}^{-1}\right)}$ \\
\hline 1 & Glifosat & 2.25 & 1,08 \\
2 & Glifosat & 3.00 & 1,44 \\
3 & Glifosat & 3.75 & 1,80 \\
4 & Glifosat & 4.50 & 2,16 \\
5 & Penyiangan Mekanis (3x) & - & - \\
6 & Kontrol (tanpa pengendalian gulma) & - & - \\
\hline
\end{tabular}


Tabel 2. Kinerja herbisida Glifosat dalam menekan \% penutupan gulma total

\begin{tabular}{|c|c|c|c|c|c|c|c|c|c|c|}
\hline \multirow{2}{*}{\multicolumn{2}{|c|}{ Perlakuan }} & \multicolumn{3}{|c|}{$4 \mathrm{MSA}$} & \multicolumn{3}{|c|}{$8 \mathrm{MSA}$} & \multicolumn{3}{|c|}{$12 \mathrm{MSA}$} \\
\hline & & \multirow{2}{*}{$\frac{\text { asli }}{4,0}$} & \multicolumn{2}{|c|}{$\begin{array}{l}\text { trans arc sin } \\
\sqrt{(x+0,5)}\end{array}$} & \multirow{2}{*}{$\begin{array}{c}\text { asli } \\
5,3\end{array}$} & \multicolumn{2}{|c|}{$\begin{array}{l}\text { trans arc sin } \\
\sqrt{\sqrt{\sqrt{ }}(\mathrm{x}+0,5)}\end{array}$} & \multirow{2}{*}{$\begin{array}{c}\text { asli } \\
3,0\end{array}$} & \multicolumn{2}{|c|}{$\begin{array}{c}\operatorname{trans} \text { arc sir } \\
\sqrt{(\mathrm{x}+0,5)}\end{array}$} \\
\hline Glifosat & $1,08 \mathrm{~kg} \mathrm{ha}^{-1}$ & & 11,25 & $\mathrm{c}$ & & 31,71 & $\mathrm{bc}$ & & 9,90 & $\mathrm{c}$ \\
\hline Glifosat & $1,44 \mathrm{~kg} \mathrm{ha}^{-1}$ & 2,3 & 8,59 & $\mathrm{c}$ & 3,5 & 28,86 & $\mathrm{c}$ & 4,5 & 12,18 & $\mathrm{c}$ \\
\hline Glifosat & $1,80 \mathrm{~kg} \mathrm{ha}^{-1}$ & 3,0 & 9,65 & $\mathrm{c}$ & 3,0 & 28,07 & $\mathrm{c}$ & 2,5 & 9,05 & $\mathrm{c}$ \\
\hline Glifosat & $2,16 \mathrm{~kg} \mathrm{ha}^{-1}$ & 2,3 & 8,13 & $\mathrm{c}$ & 2,8 & 27,30 & $\mathrm{c}$ & 3,3 & 10,10 & $\mathrm{c}$ \\
\hline Mekanis & - & 11,0 & 19,18 & $\mathrm{~b}$ & 13,0 & 36,40 & $\mathrm{~b}$ & 12,0 & 20,04 & $\mathrm{~b}$ \\
\hline Kontrol & - & 94,8 & 76,80 & $\mathrm{a}$ & 96,8 & 52,70 & $\mathrm{a}$ & 94,0 & 75,89 & $\mathrm{a}$ \\
\hline \multicolumn{2}{|l|}{ BNT } & & \multicolumn{2}{|c|}{4,13} & & \multicolumn{2}{|c|}{5,85} & \multicolumn{3}{|c|}{3,72} \\
\hline
\end{tabular}

Keterangan :MSA= Minggu setelah aplikasi; Nilai tengah pada setiap kolom yang diikuti oleh huruf yang sama tidak berbeda nyata menurut uji BNT pada taraf $5 \%$.

Tabel 3. Penekanan herbisida Glifosat terhadap \% penutupan gulma total (\%)

\begin{tabular}{|c|c|c|c|c|}
\hline \multicolumn{2}{|c|}{ Perlakuan } & $4 \mathrm{MSA}$ & $8 \mathrm{MSA}$ & $12 \mathrm{MSA}$ \\
\hline Glifosat & $1,08 \mathrm{~kg} \mathrm{ha}^{-1}$ & 95 & 94 & 97 \\
\hline Glifosat & $1,44 \mathrm{~kg} \mathrm{ha}^{-1}$ & 97 & 96 & 95 \\
\hline Glifosat & $1,80 \mathrm{~kg} \mathrm{ha}^{-1}$ & 96 & 96 & 97 \\
\hline Glifosat & $2,16 \mathrm{~kg} \mathrm{ha}^{-1}$ & 97 & 97 & 96 \\
\hline
\end{tabular}

Keterangan $\quad:$ MSA= Minggu setelah aplikasi

Tabel 4. Kinerja Herbisida Glifosat dalam Menekan Bobot Kering Gulma Total (g/0,5 m²)

\begin{tabular}{|c|c|c|c|c|c|c|c|c|c|c|}
\hline \multirow{2}{*}{\multicolumn{2}{|c|}{ Perlakuan }} & \multicolumn{3}{|c|}{$4 \mathrm{MSA}$} & \multicolumn{3}{|c|}{$8 \mathrm{MSA}$} & \multicolumn{3}{|c|}{$12 \mathrm{MSA}$} \\
\hline & & \multirow{2}{*}{$\frac{\text { asli }}{1,27}$} & \multicolumn{2}{|c|}{$\begin{array}{c}\operatorname{trans} \\
\sqrt{(x+0,5)}\end{array}$} & \multirow{2}{*}{$\frac{\text { asli }}{0,63}$} & \multicolumn{2}{|c|}{$\begin{array}{c}\text { trans } \\
\sqrt{ }\ulcorner\sqrt{ } \Gamma(x+0,5)\end{array}$} & \multirow{2}{*}{$\begin{array}{c}\text { Asli } \\
0,00\end{array}$} & \multicolumn{2}{|c|}{ 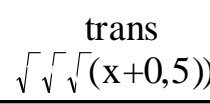 } \\
\hline Glifosat & $1,08 \mathrm{~kg} \mathrm{ha}^{-1}$ & & 1,22 & $\mathrm{~b}$ & & 0,99 & $\mathrm{bc}$ & & 0,92 & c \\
\hline Glifosat & $1,44 \mathrm{~kg} \mathrm{ha}^{-1}$ & 0,89 & 1,10 & b & 0,11 & 0,94 & $\mathrm{c}$ & 2,12 & 1,04 & $\mathrm{c}$ \\
\hline Glifosat & $1,80 \mathrm{~kg} \mathrm{ha}^{-1}$ & 0,29 & 0,87 & b & 0,87 & 0,98 & $\mathrm{bc}$ & 0,00 & 0,92 & c \\
\hline Glifosat & $2,16 \mathrm{~kg} \mathrm{ha}^{-1}$ & 0,89 & 1,08 & b & 0,01 & 0,92 & $\mathrm{c}$ & 0,67 & 0,98 & c \\
\hline Mekanis & - & 0,67 & 1,08 & b & 1,80 & 1,10 & b & 6,03 & 1,25 & b \\
\hline Kontrol & - & 33,69 & 5,83 & $\mathrm{a}$ & 35,83 & 1,56 & $\mathrm{a}$ & 26,63 & 1,49 & $\mathrm{a}$ \\
\hline BNT & & & 0,58 & & & 0,12 & & & 0,17 & \\
\hline
\end{tabular}

Keterangan : MSA= Minggu setelah aplikasi ;Nilai tengah pada setiap kolom yang diikuti oleh huruf yang sama tidak berbeda nyata menurut uji BNT pada taraf $5 \%$.

pertumbuhan gulma. Pada 8 MSA perlakuan herbisida glifosat $1,08 \mathrm{~kg} \mathrm{ha}^{-1}$ dan $1,80 \mathrm{~kg} / \mathrm{ha}$ memiliki daya kerja yang sama dengan perlakuan mekanis. Hal ini sejalan dengan penelitian Adnan (2012) dimana herbisida glifosat mampu mengendalikan gulma dengan baik hingga 42 HSA dikarenakan herbisida terserap dengan baik hingga mencapai akar sedangkan herbisida lainnya telah mengalami penurunan kemampuan pengendalian gulma. Berdasarkan Tabel 5 dapat disimpulkan bahwa perlakuan herbisida glifosat mampu menekan pertumbuhan gulma total hingga 12 MSA. Selain faktor penggunaan glifosat yang mampu menekan pertumbuhan 
gulma yang ada di pertanaman kopi, faktor agroekosistem juga sangat berpengaruh terhadap keberhasilan pengendalian.

Hal tersebut dikarenakan penggunaan pohon pelindung yang menyebabkan kondisi pada areal tersebut menjadi lebih lembab dan membatasi sinar matahari yang masuk sehingga meningkatkan toksisitas glifosat. Pada kondisi dengan kelembaban yang tinggi glifosat akan bergerak lebih mobil ke seluruh jaringan tumbuhan dan lebih cepat meracuni gulma (Ashton dan Craft, 1981). Selain itu menurut Cox (2004), herbisida glifosat membutuhkan waktu yang lama untuk terdegradasi hingga mampu menekan pertumbuhan gulma dalam jangka waktu yang panjang.

Gulma golongan daun lebar yang terdapat pada petak percobaan yaitu Asystasia gangetica, Arachis pintoi, Calapogonium mucunoides, Stachytarpheta jamaicensis, Oxalis barrelieri, Calopogonium caeruleum, Cleome rutidosperma, dan Mimosa pudica. Tabel 6 menunjukkan bahwa pada 4 dan 8 MSA perlakuan herbisida glifosat mampu menekan bobot kering gulma daun lebar sebesar 94\% - 99\%. Hal ini sesuai dengan pendapat Riadi (2011) yang menyatakan bahwa glifosat efektif dalam mengendalikan berbagai gulma termasuk gulma berdaun lebar. Selain itu, hal ini menandakan bahwa glifosat telah ditranslokasikan ke seluruh bagian gulma terutama bagian akar yang dapat menyebabkan kematian gulma tersebut secara lebih efektif (Rahe dkk., 1990 dalam Johal dan Huber, 2009). Perlakuan herbisida secara keseluruhan menunjukkan hasil yang lebih baik dalam mengendalikan gulma golongan daun lebar dibandingkan dengan perlakuan mekanis. Pada 12 MSA perlakuan herbisida glifosat mampu menekan bobot kering gulma daun lebar sebesar $82 \%-100 \%$. Perlakuan herbisida glifosat dengan dosis $1,08 \mathrm{~kg} \mathrm{ha}^{-1}$ sampai dengan $2,16 \mathrm{~kg} \mathrm{ha}^{-1}$ masih mampu menekan pertumbuhan gulma daun lebar. Sedangkan perlakuan mekanis tidak menunjukkan perbedaan bobot kering dengan kontrol yang berarti perlakuan mekanis tidak lagi mampu mengendalikan pertumbuhan gulma daun lebar pada 12 MSA (Tabel 7).

Tabel 5. Penekanan herbisida Glifosat terhadap bobot kering gulma total (\%)

\begin{tabular}{|c|c|c|c|}
\hline Perlakuan & $4 \mathrm{MSA}$ & $8 \mathrm{MSA}$ & 12 MSA \\
\hline $1,08 \mathrm{~kg} \mathrm{ha}^{-1}$ & 96 & 98 & 100 \\
\hline Gl if osat $1,44 \mathrm{~kg} \mathrm{ha}^{-1}$ & 97 & 99 & 92 \\
\hline $1,80 \mathrm{~kg} \mathrm{ha}^{-1}$ & 99 & 97 & 100 \\
\hline $2,16 \mathrm{~kg} \mathrm{ha}^{-1}$ & 97 & 99 & 97 \\
\hline
\end{tabular}

Keterangan : MSA = Minggu setelah aplikasi

Tabel 6. Kinerja Herbisida Glifosat dalam Menekan Bobot Kering Gulma Golongan Daun Lebar (g/0,5 m²).

\begin{tabular}{|c|c|c|c|c|c|c|c|c|c|c|}
\hline \multirow{2}{*}{\multicolumn{2}{|c|}{ Perlakuan }} & \multicolumn{3}{|c|}{$4 \mathrm{MSA}$} & \multicolumn{3}{|c|}{$8 \mathrm{MSA}$} & \multicolumn{3}{|c|}{$12 \mathrm{MSA}$} \\
\hline & & \multirow{2}{*}{$\begin{array}{c}\text { asli } \\
0,55\end{array}$} & \multicolumn{2}{|c|}{$\begin{array}{c}\text { trans } \\
\sqrt{\sqrt{\sqrt{(}(x+0,5)}}\end{array}$} & \multirow{2}{*}{$\begin{array}{c}\text { asli } \\
0,63\end{array}$} & \multicolumn{2}{|c|}{$\begin{array}{c}\text { trans } \\
\sqrt{\sqrt{\sqrt{(}(\mathrm{x}+0,5)}}\end{array}$} & \multirow{2}{*}{$\begin{array}{c}\text { asli } \\
0,00\end{array}$} & \multicolumn{2}{|c|}{$\begin{array}{c}\text { trans } \\
\sqrt{ }\ulcorner\sqrt{ }(\mathrm{x}+0,5))\end{array}$} \\
\hline Glifosat & $1,08 \mathrm{~kg} \mathrm{ha}^{-1}$ & & 0,98 & b & & 0,99 & $\mathrm{bc}$ & & 0,92 & $\mathrm{c}$ \\
\hline $\mathrm{Gl}$ ifosat & $1,44 \mathrm{~kg} \mathrm{ha}^{-1}$ & 0,89 & 1,01 & $b$ & 0,11 & 0,94 & $\mathrm{c}$ & 2,11 & 1,04 & $\mathrm{bc}$ \\
\hline Glifosat & $1,80 \mathrm{~kg} \mathrm{ha}^{-1}$ & 0,03 & 0,92 & $b$ & 0,87 & 0,99 & $\mathrm{bc}$ & 0,00 & 0,92 & c \\
\hline Glifosat & $2,16 \mathrm{~kg} \mathrm{ha}^{-1}$ & 0,88 & 1,00 & $\mathrm{~b}$ & 0,01 & 0,92 & $\mathrm{c}$ & 0,67 & 0,98 & $\mathrm{c}$ \\
\hline Mekanis & - & 0,63 & 1,01 & $\mathrm{~b}$ & 1,68 & 1,09 & $b$ & 5,54 & 1,21 & $a b$ \\
\hline Kontrol & - & 16,05 & 1,38 & $\mathrm{a}$ & 24,27 & 1,46 & $\mathrm{a}$ & 12,36 & 1,37 & $\mathrm{a}$ \\
\hline \multicolumn{2}{|l|}{ BNT } & & \multicolumn{2}{|c|}{0,12} & \multicolumn{3}{|c|}{0,14} & & \multicolumn{2}{|c|}{0,18} \\
\hline
\end{tabular}

Keterangan : MSA= Minggu setelah aplikasi ;Nilai tengah pada setiap kolom yang diikuti oleh huruf yang sama tidak berbeda nyata menurut uji BNT pada taraf $5 \%$. 
Tabel 7. Penekanan Herbisida Glifosat terhadap Bobot Kering Gulma Golongan Daun Lebar (\%)

\begin{tabular}{|c|c|c|c|c|}
\hline \multicolumn{2}{|c|}{ Perlakuan } & $4 \mathrm{MSA}$ & $8 \mathrm{MSA}$ & $12 \mathrm{MSA}$ \\
\hline Glifosat & $1,08 \mathrm{~kg} \mathrm{ha}^{-1}$ & 96 & 97 & 100 \\
\hline Glifosat & $1,44 \mathrm{~kg} \mathrm{ha}^{-1}$ & 94 & 99 & 82 \\
\hline Glifosat & $1,80 \mathrm{~kg} \mathrm{ha}^{-1}$ & 99 & 96 & 100 \\
\hline Glifosat & $2,16 \mathrm{~kg} \mathrm{ha}^{-1}$ & 94 & 99 & 94 \\
\hline
\end{tabular}

Keterangan $\quad$ MSA= Minggu setelah aplikasi

Tabel 8. Kinerja Herbisida Glifosat dalam Menekan Bobot Kering Gulma Golongan Rumput (g/0,5 m²)

\begin{tabular}{|c|c|c|c|c|c|c|c|c|}
\hline \multirow{2}{*}{\multicolumn{2}{|c|}{ Perlakuan }} & \multicolumn{2}{|c|}{$4 \mathrm{MSA}$} & \multicolumn{2}{|c|}{$8 \mathrm{MSA}$} & \multicolumn{3}{|c|}{$12 \mathrm{MSA}$} \\
\hline & & asli & $\begin{array}{c}\operatorname{trans} \\
\sqrt{ } \sqrt{ } \sqrt{(x+0,5)}\end{array}$ & asli & 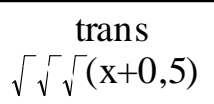 & asli & $\begin{array}{c}\text { trans } \\
\sqrt{\sqrt{ } \sqrt{v}(\mathrm{x}+0,5}\end{array}$ & \\
\hline Glifosat & $1,08 \mathrm{~kg} \mathrm{ha}^{-1}$ & 0,72 & $0,98 \quad \mathrm{~b}$ & 0,00 & $0,92 \quad \mathrm{~b}$ & 0,00 & 0,92 & $\mathrm{~b}$ \\
\hline Glifosat & $1,44 \mathrm{~kg} \mathrm{ha}^{-1}$ & 0,00 & $0,92 \quad b$ & 0,00 & 0,92 & 0,00 & 0,92 & $\mathrm{~b}$ \\
\hline Glifosat & $1,80 \mathrm{~kg} \mathrm{ha}^{-1}$ & 0,26 & $0,96 \quad b$ & 0,00 & 0,92 & 0,00 & 0,92 & $\mathrm{~b}$ \\
\hline Glifosat & $2,16 \mathrm{~kg} \mathrm{ha}^{-1}$ & 0,00 & $0,92 \quad b$ & 0,00 & 0,92 & 0,00 & 0,92 & $\mathrm{~b}$ \\
\hline Mekanis & - & 0,04 & $0,93 \quad \mathrm{~b}$ & 0,12 & 0,94 & 0,50 & 0,99 & $\mathrm{~b}$ \\
\hline Kontrol & - & 17,65 & 1,33 a & 11,56 & 1,32 & 14,27 & 1,36 & $\mathrm{a}$ \\
\hline BNT & & & 0,19 & & 0,10 & & 0,09 & \\
\hline
\end{tabular}

Keterangan : MSA= Minggu setelah aplikasi ;Nilai tengah pada setiap kolom yang diikuti oleh huruf yang sama tidak berbeda nyata menurut uji BNT pada taraf $5 \%$.

Tabel 9. Penekanan Herbisida Glifosat terhadap Bobot Kering Gulma Golongan Rumput (\%)

\begin{tabular}{ccccc}
\hline \multicolumn{2}{c}{ Perlakuan } & 4 MSA & 8 MSA & 12 MSA \\
\hline Glifosat & $1,08 \mathrm{~kg} \mathrm{ha}^{-1}$ & 96 & 100 & 100 \\
Glifosat & $1,44 \mathrm{~kg} \mathrm{ha}^{-1}$ & 100 & 100 & 100 \\
Glifosat & $1,80 \mathrm{~kg} \mathrm{ha}^{-1}$ & 98 & 100 & 100 \\
Glifosat & $2,16 \mathrm{~kg} \mathrm{ha}^{-1}$ & 100 & 100 & 100 \\
\hline
\end{tabular}

Keterangan $\quad:$ MSA= Minggu setelah aplikasi

Gulma golongan rumput yang terdapat pada petak percobaan yaitu Ottochloa nodosa, Axonophus compressus, Cyrtococcum accrescens, Imperata cylindrica, dan Setaria plicata. Tabel 8 dan 9 menunjukkan bahwa pada 4, 8 dan 12 MSA perlakuan herbisida glifosat mampu menekan bobot kering gulma golongan rumput sebesar $96 \%-100 \%$. Seluruh perlakuan herbisida dan perlakuan mekanis mampu menekan pertumbuhan gulma golongan rumput dengan baik. Perlakuan mekanis menunjukkan kinerja yang sama baiknya dengan herbisida glifosat yang diplikasikan pada petak perlakuan herbisida glifosat 1,08-2,16 $\mathrm{kg} \mathrm{ha}^{-1}$.

Dengan demikian seluruh perlakuan herbisida glifosat mampu menekan pertumbuhan gulma golongan rumput dengan baik sampai dengan 12 MSA tetapi tidak terdapat perbedaan antar perlakuan. Gulma golongan rumput merupakan tumbuhan yang pada dasarnya tidak tahan naungan, sehingga kondisi areal pertanaman kopi yang menggunakan pohon pelindung menyebabkan gulma tersebut menjadi lemah dan lebih rentan. Selain itu, setelah aplikasi pada foliar gulma, maka glifosat akan ditranslokasikan dan terakumulasi pada jaringan muda gulma (Franz dkk., 1997 dalam Tesfamariam dkk., 2009). Dengan demikian pada saat aplikasi herbisida glifosat, gulma rumput tersebut dapat dengan baik dan cepat terkendali.

Selama pengamatan yang dilakukan pada 2 MSA, 4 MSA dan 6 MSA tidak ditemukan adanya gejala fitotoksisitas yang ditunjukkan oleh tanaman kopi. Hal tersebut ditunjukkan dengan tidak ditemukannya 
perubahan warna dan bentuk daun muda tanaman kopi. Tidak ditemukannya gejala keracunan pada tanaman kopi dapat disebabkan oleh cara aplikasi yang baik dan benar sehingga cairan herbisida yang disemprotkan tidak mengenai tubuh tanaman kopi.

\section{KESIMPULAN}

Hasil penelitian menunjukkan bahwa aplikasi herbisida glifosat pada dosis $1,08-2,16 \mathrm{~kg} \mathrm{ha}^{-1}$ mampu menekan penutupan dan bobot kering gulma total, bobot kering gulma golongan daun lebar, dan golongan rumput hingga 12 MSA. Perlakuan herbisida glifosat yang digunakan untuk mengendalikan gulma tidak meracuni tanaman kopi hingga 6 MSA.

\section{SANWACANA}

Penulis mengucapkan terima kasih kepada Ir. Herry Susanto, M. P. atas saran yang diberikan.

\section{DAFTAR PUSTAKA}

Adnan. 2012. Aplikasi Beberapa Dosis Herbisida Glifosat dan Paraquat pada Sistem Tanpa Olah Tanah (Tot) serta Pengaruhnya terhadap Sifat Kimia Tanah, Karakteristik Gulma dan Hasil Kedelai. J. Agrista 16 (3) : 135-145.

Ashton,F.M. and S. Craft. 1981. Mode of Action Herbicides. A Wiley-Interscience Publication. $525 \mathrm{hlm}$.

Cox, C. 2004. Glyphosate Factsheet. J. of Pesticides Reform 24(4) : 10-13.
Direktorat Jenderal Perkebunan Kementrian Pertanian RI. 2012. Intensifikasi dan Perluasan Tanaman Kopi di Sentra Produksi Kopi. http:// ditjenbun.deptan.go.id/tanregar/berita-190intensifikasi-dan-perluasan-tanaman-kopi-disentra-produksi-kopi.html. Direktorat Jenderal Perkebunan Kementrian Pertanian RI.

Johal, G.S dan D.M. Huber. 2009. Glyphosate effects on diseases of plants. Europ. J. Agronomy 31 (1) : 144-152 .

Mas'ud, H. 2009. Komposisi dan Efisiensi Pengendalian Gulma pada Pertanaman Kedelai dengan Penggunaan Bokashi. J. Agroland 16 (2) : 118 - 123.

Riadi, M. 2011. Mata Kuliah: Herbisida dan Aplikasinya. Bahan Ajar. Universitas Hasanuddin. $138 \mathrm{hlm}$.

Tesfamariama,T., S. Botta, I. Cakmakb, V. Römhelda, dan G. Neumanna. 2009. Glyphosate in the rhizosphere-Role of waiting times and different glyphosate binding forms in soils for phytotoxicity to non-target plants. Europ. J. Agronomy 31 (1) : 126-132.

Tjitrosoedirdjo, S., I.H. Utomo, dan J. Wiroatmodjo. 1984. Pengelolaan Gulma di Perkebunan. PT. Gramedia. Jakarta. 209 hlm.

Tomlin, C.D.S. 2004. The Pesticides Manual version 5.0 (fifthteen edition). British Crop Protection Council. hlm 589. 